\title{
Comparative Evaluation of Sonicated Shrimp Waste Hydrolysates as Potential Fertilizers for Legumes
}

\author{
John Rojas', Julian Quintero, and Yhors Ciro \\ Department of Food, College of Pharmaceutical \& Food Sciences, \\ University of Antioquia, Medellin, Columbia

\section{Javier Silva \\ Department of Chemistry, College of Exact and Natural Sciences, University of Antioquia, Medellín, Columbia}

Additional index words. legume nutrition, organic fertilizers, shrimp waste exoskeletons, ultrasound-assisted hydrolysis

\begin{abstract}
The global annual production of shrimp is nearly 4.8 million metric tons, generating almost half this weight in waste. The aim of this study was to assess the development and crop production of legumes fertilized with alkaline sonicated shrimp waste under greenhouse conditions. Plants were grown separately under the following fertilization regimes: untreated soil, untreated cotton substrate, two commercial fertilizers [commercial organic fertilizer (COF) and commercial synthetic fertilizer (CSF)], and shrimp waste having hydrolysis degrees of $0 \%, 15 \%, 18 \%$, and $25 \%$. Electrical conductivity of shrimp-based fertilizers (SBFs) decreased with hydrolysis degree. However, $\mathrm{pH}(6.7-6.9)$, densification $\left(0.2-0.3 \mathrm{~g} \cdot \mathrm{cm}^{-3}\right)$ and conductivity $(10-21$ $\boldsymbol{\mu S} \cdot \mathbf{c m}^{-1}$ ) of soil was unaffected by fertilization. Furthermore, CSF had the greatest ionic exchange capability. Sonolysis resulted in an assimilable source of $\mathrm{C}, \mathrm{N}$, and $\mathrm{O}$, mainly derived from carbohydrates and proteins, and increased the availability of minerals such as $\mathrm{Ca}$ and phosphate. The greatest plant growth in both legumes was achieved when treated with CSF, whereas the raw shrimp waste caused a beneficial plant growth and crop yield mainly for Phaseolus vulgaris. All fertilizers showed typical type II isotherms, and soil substrate per se exhibited the largest water uptake. The soil microbiota increased during the growing cycle and then decreased as the reproductive phase started. In fact, soil planted with Phaseolus vulgaris showed a greater microbial population than Pisium sativum. These shrimp waste hydrolysates can be used as alternative organic soil fertilizers and are suggested as substitutes for synthetic fertilizers.
\end{abstract}

Leguminous crops have been used for numerous centuries as a food source for animals and humans (Brink and Belay, 2006). These vines are native from the Americas but they are now cultivated all over the world as a result of their high nutritional and gastronomic value. In fact, they contain high quantities of protein, vitamins (i.e., thiamine, pyridoxine, and folic acid), complex carbohydrates (i.e., starch), dietary fiber, and minerals such as $\mathrm{Fe}, \mathrm{Ca}, \mathrm{P}, \mathrm{Se}$, and Mo. They are also low in $\mathrm{Na}$ and calories (Valdez-Perez et al., 2011).

These legumes are so vital for human nutrition that $\approx 12$ million metric tons of Phaseolus vulgaris are consumed every year worldwide. Moreover, in 2014, the United States produced more than $86,700 \mathrm{t}$ of kidney beans alone. In fact, every day, $\approx 14 \%$ of the U.S.

\footnotetext{
Received for publication 2 Apr. 2019. Accepted for publication 24 May 2019

We are grateful to Colciencias for providing the financial resources for the execution of this study through grant no. 111571551545 and contract no. 036-2016. We thank CODI for their sustainability strategy 2018-19 of University of Antioquia. ${ }^{1}$ Corresponding author. E-mail: jrojasca@gmail. com.
}

population eats dry comestible beans. Legumes are a crucial part of food security across the world, especially in many developing countries. Thus, $\approx 400$ million people in the tropics eat beans as part of their daily diet. Legumes also provide income for millions of individuals, typically in Latin America and Africa.

The growth of leguminous crops would require appropriate quantities of nutrients for their optimal development; otherwise, physiological deficiency signs might occur (Takahashi, 1981). Currently, the main trend is to use organic fertilizers for vegetable growth and development. However, the heterogeneity of the physical and chemical characteristics of the different organic fertilizers may give rise to different crop yields. Interestingly, legumes are known to be $\mathrm{N}$ fixers because they take $\mathrm{N}$ from the atmosphere by demand and release it into the soil, fulfilling their own $\mathrm{N}$ needs. This implies the need for an organic fertilizer that delivers low levels of $\mathrm{N}$ accordingly (Aminul et al., 2016). For this reason, the intense use of chemical fertilizers for plant development is not prudent because it causes depletion of beneficial soil microbiota and the potential pollution of soil and water (Derkowska et al., 2015).

Currently, organic fertilizers derived from manure, worm castings, peat, and poultry guano have been used to attain efficient organic crop production of several plant species (Aluko et al., 2014). They increase the organic matter and microorganism activity, and improve porosity, water retention, and ion exchange capabilities of the soil (Esmaeilzadeh and Gholamalizadeh, 2014). They also prevent root burning or destruction of soil microflora because they contain amino acids, organic matter, and a variety of micronutrients that replenish the nutrient level of the soil, and they nourish important soil microorganisms (Ghimire, 2002). For instance, the application of vermicompost in soil decreases root decomposition of beans and produces vigorous plants (Leon et al., 2006).

Sonolysis is an emerging technology defined as the science and technology of applying sound waves with frequencies above human hearing ability, essentially from 20 to $100 \mathrm{kHz}$. Usually, these power ultrasounds have an intensity of more than $1 \mathrm{~W} \cdot \mathrm{m}^{-2}$, making them effective for hydrolysis of a wide range of complex molecules, including carbohydrates and proteins with a high molecular weight and long chain length (Mahvi, 2009). Therefore, this technology is easily adaptable in diverse fields and could be applied for hydrolysis of shrimp waste. Thus, bubbles form, expand, and contract inside the waste particles in a process called cavitation. Ultrasound eventually ruptures the bubbles, damaging the particles. As a result, particles are broken down into shorter and more nutritious compounds assimilable by plants.

Currently, the global annual production of shrimp is nearly 4.8 million metric tons, generating almost half this weight in waste mainly in the coastlines were they are farmed. This issue is more striking in world regions such as Southeast Asia (39.8\%), China $(28.3 \%)$, and India $(12 \%)$, who are the main players in trade and consumption (Anderson et al., 2017). Shrimp waste, in turn, is composed of chitin, which forms microfibrillar arrangements embedded in a protein matrix coupled with $\mathrm{CaCO}_{3}$. A green alternative for the use of this waste material is its transformation it into an organic fertilizer using controllable ultrasonic hydrolysis. The search for new SBFs is important in coast sites because of the limited availability of manure and compost in these regions. In turn, the economic and rapid sonication processes ensure the development of an organic fertilizer achieving a high degree of sustainability using these methods. Currently, there is no information regarding the organic cultivation of legumes in soils amended with SBFs.

The two main objectives of the current study were 1) to identify the effect of ultrasoundassisted hydrolysis on the nutritional and microbial content of SBFs, and 2) to assess the development of legumes treated with these fertilizers under greenhouse conditions following an organic production. Fertility and substrate management in organic greenhouse production is important in short-term crops and low-fertility soils. The development of organic fertilizers containing specific nutrients could improve crop management of 
legumes produced organically in container production systems.

\section{Materials and Methods}

Ultrasound-assisted hydrolysis of shrimp waste and experimental design. This study was conducted with Penaeus vannamei, which is the most representative shrimp species cultivated along the Pacific coast of Columbia and Ecuador. Shrimp were caught in the seashore of Tumaco and the skeletons (heads and shells) were separated from the soft body by hand. Subsequently, shrimp skeletons were sun-dried for $8 \mathrm{~h}$, milled on a cutting mill (model 3; Willey Arthur Thomas Co., Philadelphia, PA), passed through a no. 100-mesh sieve, and submitted to high-intensity ultrasound treatments. About $2.5 \mathrm{~g}$ of sample was dispersed in $25 \mathrm{~mL} 5 \% \mathrm{w} / \mathrm{v} \mathrm{NaOH}$ and an ultrasonic probe was inserted in the container to allow for direct contact with the probe for 4,10 , and $20 \mathrm{~min}$. The respective power applied in the sonicator (Sonic, Vibracell, $750 \mathrm{~W}$ maximum power) was $22.3,35.2$ and $40 \mathrm{~W} \cdot \mathrm{cm}^{-2}$ at a frequency of $20 \mathrm{~Hz}$. These mild alkaline treatments maintain the self-life of the ultrasonic probe and preserve most of the protein nutrients of the waste (Kjartansson, et al., 2006). The hydrolyzed products were neutralized with $1 \mathrm{~N}$ $\mathrm{HCl}$, followed by vacuum filtration and drying in a convection oven (U50; Memmert, Schwabach, Germany) for $12 \mathrm{~h}$ at $60{ }^{\circ} \mathrm{C}$. The dried powder was then kept in a desiccator over silica gel until further testing.

The physicochemical and functional properties of sonicated materials were compared with those of the nonsonicated shrimp waste (F0), untreated soil substrate (SS), untreated cotton substrate (CS), COF, and CSF. F0 was obtained as described earlier, except for the alkaline and sonication treatments. Previous studies (not published) demonstrated that sonication time had no effect on the hydrolysis degree of shrimp exoskeletons, reaching only $0.1 \%$ hydrolysis. SS was obtained from a local farm and was composed of a mixture of virgin soil and rice husk at a 3:2 ratio. $\mathrm{COF}$ and CSF (labeled N-P-K, 7-2-0) corresponded to an organic and extruded synthetic fertilizer, respectively.

Treatments and cultural practices. The greenhouse study was conducted in a nontemperature-controlled agricultural research station near Medellin (lat. $6.12^{\circ} \mathrm{N}$, long. $-75.54^{\circ} \mathrm{E}$; altitude, $2550 \mathrm{~m}$ ) with a $4 \times$ 4-m (width $\times$ length) greenhouse surrounded by $10-\mathrm{mm}$ light-diffusing template glass. The growing conditions in the greenhouse were a mean temperature of $23^{\circ} \mathrm{C}$ day $/ 15^{\circ} \mathrm{C}$ night and a relative humidity of $65 \%$ to $85 \%$, as recorded during the growth season. No supplementary light or heating was applied in the greenhouse station.

The soil used in the study was a mixture of fine loam (taken from $0-30 \mathrm{~cm}$ of virgin soil) and rice husk at a 3:2 ratio. The soil was put in 2-kg polyvinylchloride pots (diameter, 15 $\mathrm{cm}$ ). Vigorous and mature legume seeds were obtained from a retail center in Medellin. Subsequently, one seed was sown in each pot randomly and irrigated uniformly with tap water. A plastic saucer was placed under each pot to prevent water loss by leaching. The plants were irrigated using one dripper per plant (at a discharging rate of $10 \mathrm{~mL} \cdot \mathrm{h}^{-1}$ ); total daily irrigation during the upward season ranged from 240 to $350 \mathrm{~mL} /$ plant. The irrigation volume ensured soil was maintained wet in the growing medium.

After sprouting, only vigorous seedlings were selected for growth in each pot. Five replications of each treatment were arranged in a fully randomized design. The germinated seeds were then treated with $\approx 4 \mathrm{~g}$ of the fertilizers in three amendments and these treatments were started on 1-week-old legume seedlings that emerged from direct seeding [12 d after direct seeding (DADS)] (Silva et al., 2013). Four and 8 weeks after direct seeding, a second and third treatment was applied, whereas in the control treatment, no fertilizer was added (water only) (Romanyà et al., 2012). The composition and physical properties of the fertilizers are listed in Table 1. Legume plants were trained to a single vertical wooden pole around the main stem $1.5 \mathrm{~m}$ high from the ground to support the plant. There was no need to apply pesticides to control insects because plants were healthy and grew normally.

Plant growth and yield measurements. Plant height was evaluated on a monthly basis during the crop cycle. Harvesting started 90 DADS and finished 110 DADS. Legume plants were harvested twice a week when they reached maturity. Yield parameters measured for crop performance included pod weight, seed weight, pod length, and pod number (Islam et al., 2016). The soil samples for chemical and microbiological analyses were collected from the surface layer $(0-10 \mathrm{~cm})$.

Nutrient content of fertilizers and soil samples. The $\mathrm{pH}$ of the $1 \% \mathrm{w} / \mathrm{v}$ fertilizer dispersion was measured with a handheld combination electrical (EC) and $\mathrm{pH}$ meter (EC600; Extech Instruments, Melrose, MA) (American Society of Testing and Materials, 1995). The moisture content of the materials was obtained by gravimetric methods using a moisture balance analyzer (MB200; Ohaus, Parsippany, NJ) equipped with a halogen lamp at $120{ }^{\circ} \mathrm{C}$. The sensitivity of the measurements was $0.01 \%$ (Lekshmi et al., 2014). The total ash content was determined following the methodology described by the Association of Official Analytical Chemists. Briefly, samples were heated in a muffle oven (N31R; Mueller \& Krempel, Nabertherm, Germany) at $550{ }^{\circ} \mathrm{C}$ for $7 \mathrm{~h}$ (Association of Official Analytical Chemists, 2005b). The amount of the cooled residue was taken as the total ash content. Sugar content was determined using the phenol-sulfuric acid colorimetric method (Albalasmeh et al., 2013). The protein content was determined using the Kjeldahl method. Briefly, samples were digested with concentrated sulfuric acid, releasing $\mathrm{N}$, which was then determined by titration technique. The protein content was found by multiplying the $\mathrm{N}$ content by 6.25 (Association of Official Analytical

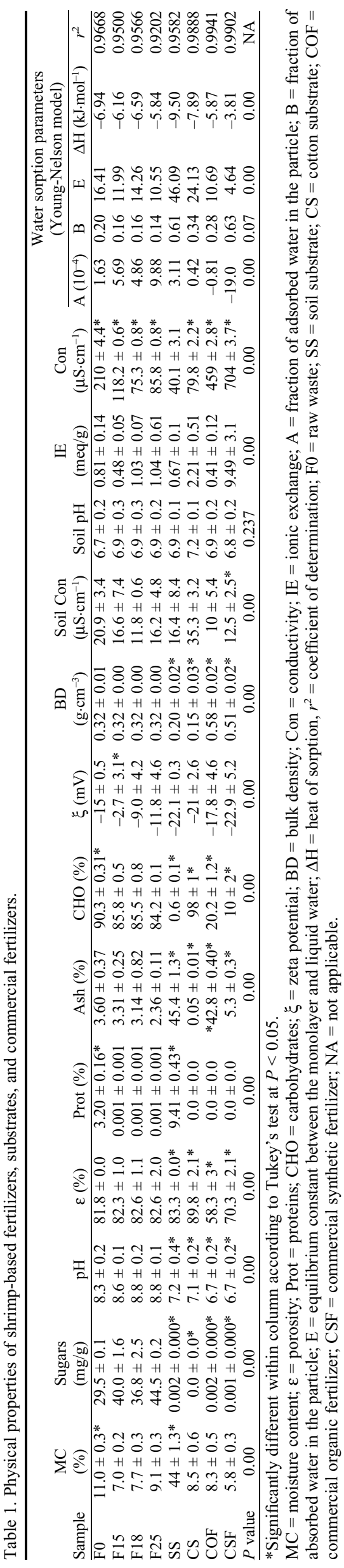

HortScience Vol. 54(9) September 2019 
Chemists, 2005a). Total carbohydrate content was calculated as the difference from the other constituents in the fertilizer (protein, fat, water, alcohol, ash) (Association of Official Analytical Chemists, 2005c).

The elemental analysis of the fertilizers was conducted by energy-dispersive X-ray analysis (JEOL 6490LV; Peabody, MA). About $0.2 \mathrm{~g}$ of the samples was evenly spread over an aluminum stub. Subsequently, samples were sputtercoated with a gold alloy for 5 min using a vacuum chamber (Desk IV; Denton Vacuum, Moorestown, NJ) operated at a potential of $15 \mathrm{kV}$. X-ray diffraction $\left(\mathrm{CuK} \alpha_{1}\right.$ radiation $)$ scanned the sample surface at a depth of field of $10 \mathrm{~mm}$, with $50-\mu \mathrm{m}$ penetration for $300 \mathrm{~s}$. A Malvern Nano-ZS90 Zetasizer equipped with Zetasizer software (version 7.11; Malvern Instruments Ltd., UK) was used to determine the zeta potential or particle charge at $25^{\circ} \mathrm{C}$ using the principle of laser Doppler velocimetry. The zeta potential measurements were performed by adding $700 \mu \mathrm{L}$ of the sample to a polystyrene cell. Samples were analyzed between 12 and 16 cycles with a voltage of $4 \mathrm{mV}$. The ionic exchange test was carried out by weighing 0.5 to $1 \mathrm{~g}$ of sample, then $10 \mathrm{~mL} 6 \mathrm{~N} \mathrm{HCl}$ was added. This dispersion was allowed to stand for $24 \mathrm{~h}$, followed by centrifugation for $20 \mathrm{~min}$ at $1550 \mathrm{rpm}$. Subsequently, the supernatant was submitted to washing with $1 \%$ saline solution twice and titrated with $0.8 \mathrm{~N} \mathrm{NaOH}$ solution. All measurements are expressed on a dry-weight basis.

Water sorption studies. Water sorption studies were conducted using the static gravimetry method on chambers having different saturated salts rendering different relative humidities. Thus, $\mathrm{K}_{2} \mathrm{CO}_{3}, \mathrm{NaBr}, \mathrm{NaCl}, \mathrm{KCl}$, $\mathrm{KNO}_{3}$, and $\mathrm{H}_{2} \mathrm{O}$ rendered constant relative humidities of $43 \%, 58 \%, 68 \%, 75 \%, 94 \%$, and $100 \%$, respectively. The isotherms were built at $25{ }^{\circ} \mathrm{C}$ and samples were allowed to reach equilibrium for 2 weeks, when the difference between two consecutive weighings was not greater than $0.1 \%$. Data were fitted to several sorption models, and only the one that presented the best fit is discussed here. The ability of fertilizer for water sorption was studied by applying the Young and Nelson model, which is expressed as

$$
\begin{gathered}
m=m_{m}+m_{c}+m_{i} \\
m=A(\theta+\beta)+B \psi \\
\theta=\frac{a_{w}}{a_{w}+\left(1-a_{w}\right) E} \ldots \\
\psi=a_{w} \theta \\
\beta=-\frac{E a_{w}}{E-(E-1) a_{w}} \\
+-\frac{E^{2}}{(E-1)} \operatorname{Ln} \frac{E-(E-1) a_{w}}{E} \\
-(E+1) \operatorname{Ln}\left(1-a_{w}\right),
\end{gathered}
$$

where $m, \theta$, and $\psi$ correspond to the total moisture content, fraction of surface covered by a monomolecular layer, and the fraction of surface covered by a water multilayer; $\beta, H_{1}$, $H_{1}, R$, and $T$ correspond to the total amount of adsorbed moisture in the multilayer, heat of adsorption of water bound to the surface, heat of condensation, and gas constant and temperature. $A$ and $B$ are dimensionless constants related to the fraction of adsorbed and absorbed water in the particle, respectively, whereas $E$ is the equilibrium constant between the monolayer and liquid water. The product $A \theta$ is related to the amount of monolayer moisture; $A(\theta+\beta)$ is the externally absorbed moisture during the sorption phase. $B \psi$ is the amount of absorbed moisture during the sorption phase. $m_{m}, m_{c}$, and $m_{i}$ correspond to the tightly bound water, condensed external water, and internally absorbed water, respectively (Young and Nelson, 1967).

Total aerobic bacteria and fungi counts. These tests were conducted on soil substrates without any previous treatment according to National Technical Standard 4092 of microbiology. Briefly, $1 \mathrm{~g}$ of raw soil samples exhibiting a nearly neutral $\mathrm{pH}(6.7-7.2)$ was dispersed in $10 \mathrm{~mL}$ peptone water, making the pertinent dilution factors $1 \times 10^{-1}$ to $1 \times$ $10^{-10}$. Subsequently, $1 \mathrm{~mL}$ of the solution was poured onto a $20-\mathrm{mL}$ culture plate (Merck). Samples were then incubated at $37{ }^{\circ} \mathrm{C}$ between 24 and $48 \mathrm{~h}$. The results are reported as colony-forming units per gram of fertilizer.

Statistical analysis. The principal component analysis (PCA) was the type of multivariate analysis used to identify and compare the relationships and patterns among the physicochemical and functional properties of the fertilizers. The software Minitab ${ }^{\circledR}$ (version 16; Minitab, Inc., State College, PA) was used for data processing. The relationships between the different crop characteristics were assessed by the Pearson's correlation coefficient at a significance level of $P<0.05$. Additional post hoc assessment was performed using Tukey's test $(P<0.05)$ when significant differences between means were observed. The condition of normality was checked using the Shapiro-Wilk test.

\section{Results}

Preparation and characterization of the fertilizers. High-intensity, low-frequency ultrasound-generated acoustic waves, which expanded and contracted rapidly, caused chemical, physical, and mechanical degradation of shrimp waste. Furthermore, the hydroxyl radicals of the alkaline media contributed to molecular weight reduction of the waste components (i.e., carbohydrates and proteins), avoiding the need for a timeconsuming composting of the raw waste and hence, decreased the microbial population and eluded further decomposition, preventing the release of putrescine and other nitrous volatile compounds. Preliminary studies determined very low levels of carotenoids $(<1 \%$ $\mathrm{w} / \mathrm{w})$ in the raw shrimp waste; but, upon sonication, carotenoids were not detected anymore in the hydrolyzed materials. This phenomenon is explained by the high solubility of carotenoids in alkaline media, which fully extracted and washed them off the shrimp waste. In addition, the alkaline hydrolysis of shrimp waste usually requires long treatment periods and high temperatures. However, by using sonication, hydrolysis could be carried out at room temperature with a short processing time. As a result, sonication was inexpensive compared with conventional alkaline hydrolysis.

The nutritional content of the SBFs is listed in Table 1. The $\mathrm{pH}$ and moisture content of these fertilizers ranged from 8.3 to 8.8 and from $7.0 \%$ to $11 \%$, respectively. These ranges diverged from those of SS and commercial fertilizers. For instance, the SS exhibited a nearly neutral $\mathrm{pH}$ and large moisture content. Once the SBFs were incorporated into SS, the $\mathrm{pH}$ decreased, maintaining a slightly neutral ambient $(\approx 6.9)$, and $\mathrm{EC}$ ranged from $\approx 10$ to $21 \mu \mathrm{S} \cdot \mathrm{cm}^{-1}$. A neutral $\mathrm{pH}$ ensured good nutrient availability for the leguminous plants and eased the biological functionality as an organic soil amendment.

The zeta potential indicates the average charge in the particles and gives a measurement of the ion activity of the fertilizers. All materials exhibited a net negative charge; CSF exhibited the greatest ion exchange capability and EC. Conversely, SS exhibited the lowest EC values, and the SBFs showed in-between values. The latter implies a movable ion exchange capability resulting from the variable degree of hydrolysis of SBFs. Interestingly, CS showed a large ionic exchange capability but a moderate EC, resulting from the residual ionized functional groups present in this type of semicrystalline alpha cellulose. Likewise, the ash content of SS (45.4\%) and COF (61\%) was greater than that of the SBFs $(2.4 \%$ to $3.6 \%)$ mainly because of their high silicate and carbonate content. Furthermore, the ash content decreased as the hydrolyzed degree of shrimp waste increased, whereas the content of carbohydrates $(\approx 85 \%)$ and soluble sugars ( 29.5 $44.5 \mathrm{mg} \cdot \mathrm{g}^{-1}$ ) remained virtually unchanged, and proteins essentially disappeared upon hydrolysis. Moreover, densification $\left(0.32 \mathrm{~g} \cdot \mathrm{cm}^{-3}\right)$ and porosity $(82 \%)$ of SBFs were unaffected by the hydrolysis degree. CS and CSF had the lowest and greatest bulk density, respectively; and their total porosity showed an inverse trend, as expected.

The fitting water sorption parameters obtained from the Young-Nelson model revealed a good fit to this model, with an $r^{2}$ value greater than 0.9202 , compared with other models not shown in this study. Interestingly, the raw SS showed the greatest $E$ parameter, and hence presented the greatest heat of endothermic sorption $(\Delta H)$, whereas SS and CSF showed the greatest intrinsic absorbed water ( $B$ parameter). Figure 1 shows the respective water sorption isotherms. CSF and SS showed the greatest hygroscopicity, especially at a water activity more than 0.4 . Furthermore, these two samples had the greatest ability to absorb water intrinsically, whereas SS and CS per se were able to form 
large water multilayers around the particles. In addition, the water sorption behavior of SBFs was comparable to that of COF.

Table 2 lists the elemental composition of each type of SBF, substrate, and commercial fertilizers. Alkaline sonolysis had a marked effect on the nutritional content of the fertilizers. Because their source was shrimp waste, they presented a large content of mainly $\mathrm{C}, \mathrm{N}$, $\mathrm{Ca}$, and $\mathrm{P}$. On the other hand, $\mathrm{Fe}, \mathrm{Si}, \mathrm{Al}, \mathrm{Mg}$, and $\mathrm{Cl}$ were present as the main microelements. The content of $\mathrm{Mg}, \mathrm{Cl}$, and $\mathrm{Na}$ was greater in F0 than in SS, CS, and the commercial products, whereas the $\mathrm{K}$ content was low in all cases $(\approx 0.1 \%$ dry weight $)$, except for $\mathrm{COF}$. The $\mathrm{C} / \mathrm{N}$ ratio of $\mathrm{SBFs}$ remained between 2 and 3 , whereas $\mathrm{COF}$ (10.5) and SS (33.1) showed the greatest $\mathrm{C} / \mathrm{N}$ ratio. In fact, the entire $\mathrm{N}$ was in organic form and remained almost constant with hydrolysis degree. Conversely, the $\mathrm{C}$ level decreased at a hydrolysis degree greater than $18 \%$. Furthermore, SS and COF were poor in organic $\mathrm{N}$, but rich in $\mathrm{C}, \mathrm{Si}$, and $\mathrm{Al}$. On the other hand, CS had a poor content of most elements except for C and O. Surprisingly, $\mathrm{SS}$ and COF also had a large amount of $\mathrm{Si}$ and $\mathrm{Al}$ compared with the SBFs. Moreover, SS presented low levels of essential elements such as $\mathrm{N}, \mathrm{P}$, and $\mathrm{Ca}$ compared with the SBFs. Interestingly, $\mathrm{COF}$ and $\mathrm{SS}$ showed traces of other microelements such as $\mathrm{K}$ and $\mathrm{Ti}$, and essentially COF was the only fertilizer containing traces of $\mathrm{Mn}$, whereas CSF contained $\mathrm{N}$ as urea and $\mathrm{P}$ as $\mathrm{P}_{2} \mathrm{O}_{5}$ at a $7: 2$ ratio.
Figure 2 depicts legume growth as a function of time resulting in a comparable sigmoid or S-shaped profile for both plants once fertilized with SBFs. Furthermore, both legumes showed the best developing phase upon fertilization with CSF. The largest and fastest growing period corresponding to the period of rapid nutrient uptake occurred within the first month in $P$. vulgaris, whereas for $P$. sativum it occurred within the first 2 months of the crop cycle.

The pod length, pod weight, and seed weight of $P$. vulgaris were outstanding when treated with CSF, and comparable to those of F0. Conversely, crop quality of $P$. sativum as described by these parameters was superior for the unfertilized soil (SS) (Table 3). In addition, there was a direct relationship
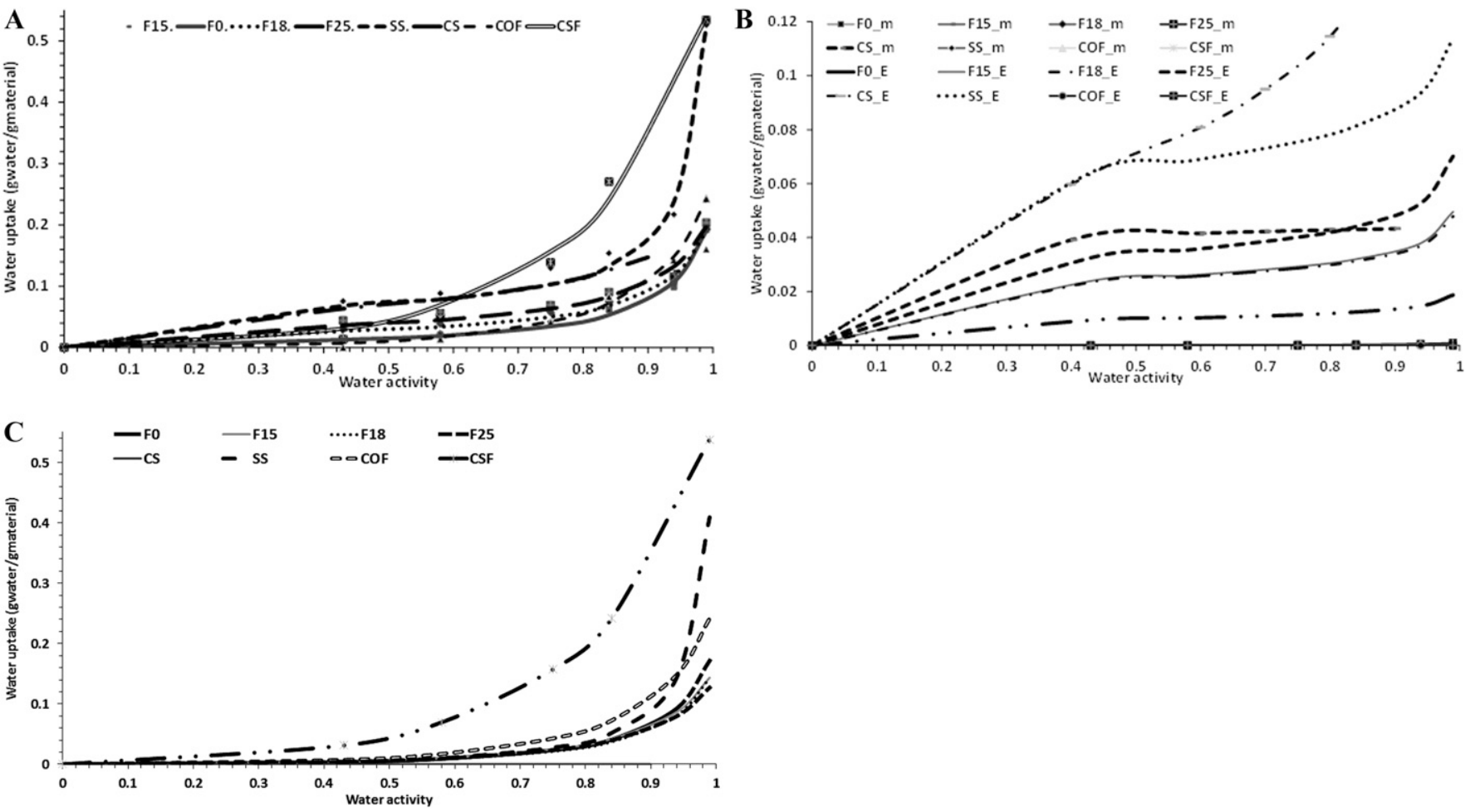

Fig. 1. Water sorption isotherms fitted to the Young-Nelson model. (A) Fitted isotherms. (B) Deconvoluted sorption behavior for the monolayer and multilayers. (C) Deconvoluted sorption behavior for the intrinsic absorbed water $(\mathrm{n}=3)$. $\mathrm{SS}=$ soil substrate; $\mathrm{CS}=$ cotton substrate; $\mathrm{CF}=$ commercial fertilizer.

Table 2. Elemental analysis of shrimp-based fertilizers, substrates, and commercial fertilizers $(\mathrm{n}=3)$

\begin{tabular}{|c|c|c|c|c|c|c|c|c|c|}
\hline Element & FO & F15 & F18 & F25 & SS & $\mathrm{CS}$ & $\mathrm{COF}$ & $\mathrm{CSF}$ & $P$ value \\
\hline$\overline{\mathrm{C}}$ & $43 \pm 3.3$ & $46.6 \pm 2.3$ & $35.9 \pm 5.7^{*}$ & $36.3 \pm 10.8$ & $33.1 \pm 1.1^{*}$ & $53.5 \pm 4.5^{*}$ & $41.0 \pm 10.3$ & $39.0 \pm 3.63$ & 0.02 \\
\hline $\mathrm{N}$ & $15.9 \pm 5.4$ & $17.9 \pm 2.6$ & $20.8 \pm 6.6$ & $19.8 \pm 4.2$ & $0 \pm 0^{*}$ & $0 \pm 0^{*}$ & $0 \pm 0^{*}$ & $15.9 \pm 4.9$ & 0.00 \\
\hline $\mathrm{Si}$ & $0.2 \pm 0.1$ & $0.2 \pm 0.2$ & $0.1 \pm 0.1$ & $0.03 \pm 0.0$ & $18.1 \pm 1.6^{*}$ & $0 \pm 0$ & $11.4 \pm 3.2^{*}$ & $0.9 \pm 0.4$ & 0.00 \\
\hline $\mathrm{Fe}$ & $1.5 \pm 1.0$ & $1.6 \pm 1.4$ & $0.3 \pm 0.2$ & $0 \pm 0$ & $1.2 \pm 0.8$ & $0 \pm 0$ & $1.8 \pm 1.8$ & $5.4 \pm 5.4$ & 0.09 \\
\hline $\mathrm{Al}$ & $0.1 \pm 0.1$ & $0.1 \pm 0.1$ & $0.2 \pm 0.1$ & $0.1 \pm 0.1$ & $4.1 \pm 0.7^{*}$ & $0.5 \pm 0.5$ & $2.7 \pm 0.5^{*}$ & $0.0 \pm 0.0$ & 0.00 \\
\hline $\mathrm{Na}$ & $0.2 \pm 0.1$ & $0.02 \pm 0.02$ & $0.2 \pm 0.1$ & $0.2 \pm 0.1$ & $0.1 \pm 0.1$ & $0 \pm 0$ & $0.8 \pm 0.2^{*}$ & $0.47 \pm 0.13^{*}$ & 0.00 \\
\hline K & $0 \pm 0$ & $0 \pm 0$ & $0 \pm 0$ & $0 \pm 0$ & $0 \pm 0$ & $0 \pm 0$ & $1.1 \pm 0.2^{*}$ & $0 \pm 0$ & 0.00 \\
\hline $\mathrm{Ti}$ & $0 \pm 0$ & $0 \pm 0$ & $0 \pm 0$ & $0 \pm 0$ & $0.5 \pm 0.5$ & $0 \pm 0$ & $0.4 \pm 0.4^{*}$ & $0 \pm 0$ & 0.00 \\
\hline $\mathrm{Mn}$ & $0 \pm 0$ & $0 \pm 0$ & $0 \pm 0$ & $0 \pm 0$ & $0 \pm 0$ & $0 \pm 0$ & $0.03 \pm 0.03$ & $0 \pm 0$ & 0.03 \\
\hline $\mathrm{C} / \mathrm{N}$ & 2.7 & 2.6 & 1.7 & 1.8 & 33.1 & 53.5 & 41 & 2.5 & NA \\
\hline
\end{tabular}

*Significantly different within column according to Tukey's test at $P<0.05$.

$\mathrm{F} 0=$ raw waste; $\mathrm{SS}=$ soil substrate; $\mathrm{CS}=$ cotton substrate; $\mathrm{COF}=$ commercial organic fertilizer; $\mathrm{CSF}=$ commercial synthetic fertilizer; NA $=$ not applicable. 
between crop quality and plant height for $P$. vulgaris, but this relationship was not evident for $P$. sativum. Moreover, the fact of having a large pod number did not necessarily translate into a large crop yield, but pod length, pod weight, and seed weight were all good indicators of crop yield for both legumes. Interestingly, CS rendered the poorest legume growth, probably as a result of the lack of essential nutrients different from $\mathrm{C}$ and $\mathrm{O}$.
Nonetheless, $P$. vulgaris was able to respond to the lack of nutrients and was capable of taking up $\mathrm{N}$ from the atmosphere.

The results obtained from the microbial tests are shown in Table 4. The SBFs, once incorporated into the soil, showed a variable microbial population that decreased over time, possibly because of the depletion of soil nutrients that share with plants in a symbiotic way. Consequently, the magnitude of the microbial population depended on the symbiosis with the leguminous plants. In fact, the bacterial population was greater in soils containing $P$. vulgaris than $P$. sativum. Conversely, the latter favored the proliferation of fungi in the soil. In addition, fertilizer also influenced bacterial proliferation. For example, COF rendered the largest bacterial population in the soil, whereas CSF maintained an essentially constant bacterial count. On the
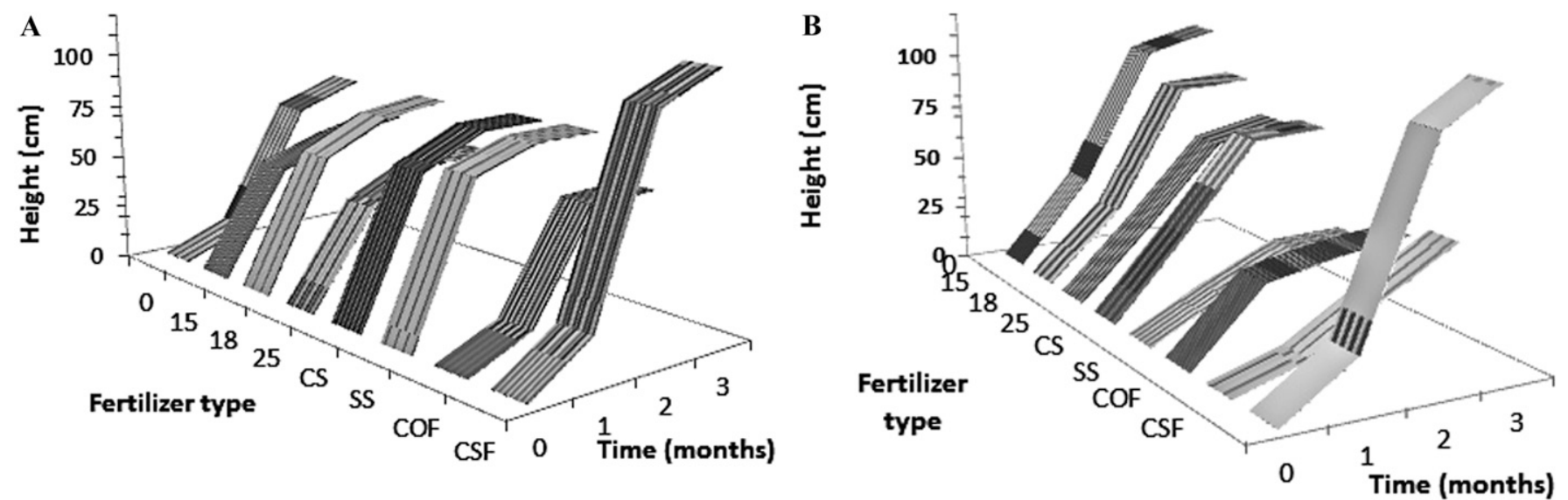

Fig. 2. Effect of shrimp-based fertilizers, substrates, and commercial fertilizers on plant growth of $(\mathbf{A})$ Phaseolus vulgaris and $(\mathbf{B})$ Pisum sativum $(\mathrm{n}=5)$. SS $=$ soil substrate; $\mathrm{CS}=$ cotton substrate; $\mathrm{CF}=$ commercial fertilizer.

Table 3. Effect of shrimp-based fertilizers, substrates, and commercial fertilizers on plant development for Phaseolus vulgaris and Pisum sativum.

\begin{tabular}{|c|c|c|c|c|c|c|c|c|}
\hline \multirow[b]{2}{*}{ Sample } & \multicolumn{4}{|c|}{ Phaseolus vulgaris } & \multicolumn{4}{|c|}{ Pisum sativum } \\
\hline & Pod length $(\mathrm{cm})$ & Pod weight (g) & Seed weight (g) & Pod number & Pod length $(\mathrm{cm})$ & Pod weight (g) & Seed weight (g) & Pod number \\
\hline F15 & $6.6 \pm 1.4$ & $3.26 \pm 1.4$ & $0.69 \pm 0.2$ & $1.8 \pm 0.8$ & $5.1 \pm 0.6^{*}$ & $0.73 \pm 0.2$ & $0.53 \pm 0.1$ & $1.25 \pm 0.8$ \\
\hline F25 & $7.8 \pm 1.4$ & $2.18 \pm 1.1$ & $0.8 \pm 0.2$ & $1 \pm 0.0$ & $7.0 \pm 1.1$ & $1.3 \pm 0.4$ & $1.08 \pm 0.3$ & $2 \pm 1$ \\
\hline SS & $4.9 \pm 1.3^{*}$ & $0.62 \pm 0.2^{*}$ & $0.35 \pm 0.1 *$ & $1 \pm 0.0$ & $6.5 \pm 1.2$ & $3.9 \pm 0.9 *$ & $1.43 \pm 0.1$ & $1 \pm 0^{*}$ \\
\hline $\mathrm{CS}$ & $4.3 \pm 1.3 *$ & $0.26 \pm 0.1^{*}$ & $0.1 \pm 0.0^{*}$ & $2 \pm 0.1$ & $5 \pm 0.5^{*}$ & $1.1 \pm 0.5$ & $0.43 \pm 0.1 *$ & $2 \pm 0.1$ \\
\hline $\mathrm{COF}$ & $7.7 \pm 1.1$ & $2.13 \pm 0.8$ & $0.73 \pm 0.1$ & $3 \pm 1.0^{*}$ & $6.0 \pm 0.8$ & $0.74 \pm 0.1$ & $0.46 \pm 0.1 *$ & $2 \pm 1^{*}$ \\
\hline
\end{tabular}

*Significantly different within column according to Tukey's test at $P<0.05$.

$\mathrm{SS}=$ soil substrate; $\mathrm{CS}=$ cotton substrate; $\mathrm{COF}=$ commercial organic fertilizer; $\mathrm{CSF}=$ commercial synthetic fertilizer.

Table 4. Total aerobic bacteria and fungi of the soil fertilized with shrimp-based fertilizers and commercial fertilizers.

\begin{tabular}{|c|c|c|c|c|c|c|c|c|c|c|c|c|c|c|c|c|}
\hline \multicolumn{17}{|c|}{ Mesoaerobic bacteria $\left(\mathrm{cfu} \times 10^{4} / \mathrm{g}\right)^{z}$} \\
\hline & \multicolumn{2}{|c|}{ F0 } & \multicolumn{2}{|c|}{ F15 } & \multicolumn{2}{|c|}{ F18 } & \multicolumn{2}{|c|}{ F25 } & \multicolumn{2}{|c|}{ SS } & \multicolumn{2}{|c|}{ CS } & \multicolumn{2}{|c|}{ CF1 } & \multicolumn{2}{|c|}{ CF2 } \\
\hline Time (mo.) & PV & PS & PV & PS & PV & PS & PV & PS & PV & PS & PV & PS & PV & PS & $\overline{\mathrm{PV}}$ & PS \\
\hline 1 & 100 & 40 & 6.5 & 7 & 2.4 & 5 & 210 & 180 & 102 & 36 & 1 & 0.2 & 580 & 370 & 12 & 32 \\
\hline
\end{tabular}

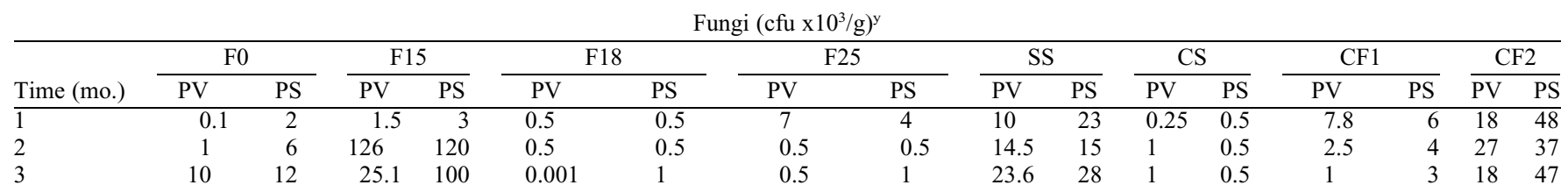

Bacteria/fungi ratio

\begin{tabular}{|c|c|c|c|c|c|c|c|c|c|c|c|c|c|c|c|c|}
\hline \multirow[b]{2}{*}{ Time (mo.) } & \multicolumn{2}{|c|}{ F0 } & \multicolumn{2}{|c|}{ F15 } & \multicolumn{2}{|c|}{ F18 } & \multicolumn{2}{|c|}{ F25 } & \multicolumn{2}{|c|}{ SS } & \multicolumn{2}{|c|}{$\mathrm{CS}$} & \multicolumn{2}{|c|}{ CF1 } & \multicolumn{2}{|c|}{ CF2 } \\
\hline & PV & PS & PV & PS & PV & PS & PV & PS & PV & PS & PV & PS & PV & PS & PV & PS \\
\hline 2 & 1,030 & 43 & 24 & 18 & $3.8 \times 10^{5}$ & $24 \times 10^{5}$ & $1.5 \times 10^{6}$ & $1.3 \times 10^{6}$ & 90 & 68 & 30 & 2 & $3.1 \times 10^{3}$ & 160 & 6 & 9 \\
\hline
\end{tabular}

${ }^{\mathrm{z}}$ Basal count: $5 \times 10^{4} / \mathrm{g}$.

${ }^{\mathrm{y}}$ Basal count: $100 / \mathrm{g}$

$\mathrm{SS}=$ soil substrate; $\mathrm{CS}=$ cotton substrate $\mathrm{COF}=$ commercial organic fertilizer; $\mathrm{CSF}=$ commercial synthetic fertilizer; $\mathrm{PV}=$ Phaseolus vulgaris $; \mathrm{PS}=$ Pisium sativum. 
contrary, the soil population of fungi tended to increase over time, except for soils treated with $\mathrm{COF}$ and $\mathrm{CSF}$, in which the populated decreased and remained almost unchanged, respectively. Moreover, the bacteria-to-fungi ratio decreased over time except for CSF, which remained practically unchanged.

\section{Discussion}

Nutritional content of the fertilizers and plant development. Shrimp waste has the striated type of muscle arranged into muscle fibers that are bound by a connective tissue; the prevailing amino acid is lysine. These muscle proteins are associated with chitin and minerals such as calcium phosphate. Protein and chitin availability are important because they eventually turn into accessible $\mathrm{N}$ for legumes. The magnitude of the peptide and glycosidic bond cleavage was controlled by the alkaline sonication, creating organic fertilizers with different degrees of hydrolysis.

The hydrolyzed products retained much of the initial nutrients contained in the raw shrimp waste, as listed in Table 1 . The alkaline ultrasound-assisted hydrolysis (AUAH) disrupted the inter- and intramolecular $\mathrm{H}$ bond pattern of complex carbohydrates and proteins initially present in the material, disturbing the regularity of the three-dimensional packing and stereochemistry between chains, especially of the most accessible amorphous regions. As a result, the AUAH of the noncrystalline fraction removed monomer blocks of repeated units, especially those located at the crystallite surface; hence, $\mathrm{NaOH}$ accessed the $\beta-1,4 \quad \mathrm{~N}$-acetyl and peptide linkages simultaneously. The net result is a reduction in the crystallinity of the shrimp waste. In fact, the application of high-intensity waves generated cavities, causing the observed chemical and mechanical effects in the waste particles, resulting in changes in the native shrimp protein and carbohydrate structure into a molten globule state and further degradation. This effect increased with sonication time, leading to a higher hydrolysis degree.

Fertilizers with a high hydrolysis degree led to more available $\mathrm{N}, \mathrm{Ca}$, and $\mathrm{P}$ because of the aperture of the proteins and depolymerization of the carbohydrate chain network. Furthermore, the $\mathrm{C} / \mathrm{N}$ ratio decreased with hydrolysis degree as a result of the degradation of carbohydrates and proteins into lowmolecular weight compounds such as glucose, sucrose, and glucosamine.

It is accepted that during the decomposition of an organic fertilizer the microbial population requires an optimal diet with a $\mathrm{C}: \mathrm{N}$ ratio of $\approx 15: 1$ to meet their needs for nutrients. Because the SBFs had a $\mathrm{C}: \mathrm{N}$ ratio of less than $15: 1$, they had more $N$ than the microflora require for their own growth in the initial crop cycle and are likely to provide significant plant-available $\mathrm{N}$, leading to increased mineral $\mathrm{N}$ levels through mineralization carried out by microbial metabolism (production of $\mathrm{NH}_{4}^{+}$and $\mathrm{NO}_{3}^{-}$) (Eroa,
2015). This phenomenon was reflected on a large microbial population in the soil within the first month $(>50,000 \mathrm{cfu} / \mathrm{g}$ of bacteria and $>100 \mathrm{cfu} / \mathrm{g}$ for fungi). Conversely, SS alone had a C:N ratio of more than $25: 1$, and thus it a rapid immobilization of the scarce $\mathrm{N}$ by microorganisms in this growing phase is assumed (Chavan et al., 2015). Moreover, SS per se had an innate deficit in N and $\mathrm{P}$, and thus it was imperative we add these SBFs because of the high content of these elements, especially N. Furthermore, because the N content was greater than $2.5 \%$, these SBFs are expected to release nutrients once decomposed by the microbiota of the soil. The $\mathrm{N}-\mathrm{P}-$ $\mathrm{K}$ values of the SBFs and SS were 1-0.1-0.0 and $0-0-0.1$, respectively. These ratios are different from others reported for organic fertilizers, such as cow manure $(0.97-0.69$ $1.66)$ and compost of raw straw $(0.81-0.18$ $0.68)$.

In all cases, the $\mathrm{pH}$ of the soil upon application of these organic fertilizers ranged from 6.7 to 6.9 and, along with high moisture content, eased the transformation of macromolecular $\mathrm{N}$ into $\mathrm{NH}_{4}{ }^{+}$and $\mathrm{NO}_{3}{ }^{-}$by bacterial action, resulting in its mineralization and easy uptake by plants as reported previously (Tucker, 2015). In fact, the SBFs showed a slightly alkaline $\mathrm{pH}$, but the soil exerted a diluting effect, keeping a nearly neutral environment during the crop cycle. The alkaline $\mathrm{pH}$ of the SBFs is attributed to the presence of peptides, and elements such as $\mathrm{Ca}^{2+}$ and $\mathrm{Mg}^{2+}$. Furthermore, these divalent ions can then be adsorbed onto the surface of tiny clay particles in the soil, which had a net negative charge. The $\mathrm{Mg}$ level in the SBFs was less than that of $\mathrm{Ca}$, so its effect on the soil structure remained negligible. The negative surface charge of soil particles is believed to improve $\mathrm{P}$ availability in form of phosphates as present in the SBFs. This phenomenon has been attributed to competition between the decomposition products of organic matter and $\mathrm{P}$ for soil sorption sites, resulting in increased soil solution $P$ levels (Guppy et al., 2005). These phosphates, along with the $\mathrm{P}_{2} \mathrm{O}_{5}$ of CSF, could be responsible for the large $P$. vulgaris crop yield found in F0 and CSF, respectively. Conversely, $\mathrm{K}$ was virtually absent in most fertilizers and its synergistic effect on crop yield was not noticed.

The SBFs were applied at a rate of $4 \mathrm{~g} \cdot \mathrm{kg}^{-1}$ soil in three monthly amendments. The SBFs, having $15 \%$ to $20 \% \mathrm{~N}$, had a variable effect on legume growth features depending on the hydrolysis degree. As a result, they showed distinctive quantitative and qualitative traits of grain yield of legumes, especially for $P$. vulgaris. It has been reported that a large amendment of $20 \%$ of organic fertilizer (vermicompost) was needed to get the greatest pod weight, pod number, pod dry weight, and pod length of legumes (Aminul et al., 2016). In our study, there was a remarkable mismatch between plant growth and plant yield. For instance, CSF and F0 rendered plants with an optimal growth and crop yield, especially for $P$. vulgaris, whereas
CSF only led to good plant growth rather than crop yield in $P$. sativum. This is explained by the content of urea: $\mathrm{P}_{2} \mathrm{O}_{5}(\mathrm{~N} / \mathrm{P}$ ratio, 13.2), which is recommended by the supplier for rapid plant growth. In all cases, $\mathrm{N}$ uptake and growth rate were prominent within 30 and $60 \mathrm{~d}$ after sowing. In other words, the growth rate increased progressively over time during the vegetative growth up to 4 to 8 weeks, after which growth slowed down as the reproductive phase initiated. Legume growth was not significantly improved with most SBFs, despite having a considerable content of available $\mathrm{N}$ because of the slow release of this element. However, macroelements such as $\mathrm{N}, \mathrm{C}, \mathrm{P}$, and $\mathrm{Ca}$ were available at $45 \mathrm{~d}$ after sowing for the appropriate blooming and protein development. Interestingly, unfertilized CS showed the slowest development and lowest crop quality for both legumes, especially for $P$. sativum and, consequently, this plant was not very efficient as an atmospheric $\mathrm{N}$ fixer to compensate for the lack of $\mathrm{N}$ in $\mathrm{CS}$. In this case, the branched root hair systems of the legumes were not sufficient to ease $\mathrm{N}$ mineralization during the growing phase and, as a result, $P$. sativum showed the poorest crop yield.

Soil microstructure and microbial activity. The EC of the organic fertilizers decreased during the hydrolysis process compared with $\mathrm{F} 0$ as a result of leakage of some ions such as $\mathrm{Ca}$ and phosphates. Furthermore, the incorporation of these fertilizers into the soil did not have a marked effect on the physicochemical properties of the soil as a result of a dilution effect. Thus, the EC of the soil was low $\left(10-21 \mu \mathrm{S} \cdot \mathrm{cm}^{-1}\right)$ compared with the pure fertilizers, but outside the range recommended for other horticultural plants (0.76-4.0 mS. $\left.\mathrm{cm}^{-1}\right)$ (Nelson, 2011).

The zeta potential is a measurement of the total charge of a particle in solution. The negative charge of the SBFs is a result of the residual amine groups of chitin and amino acids. It was expected that complex carbohydrates present in SBFs such as chitin could act as cementing agents, bonding soil particles together and improving soil structure and stability. It is also reported that $\mathrm{Ca}$ ions could act as cementing agent, bonding soil particles into aggregates and resulting in the formation of strong, water-stable aggregates (Yang et al., 2016). However, the net postharvest bulk density of the soil did not vary significantly upon treatment with fertilizers, probably because of the low applied rate, and density remained in the range generally considered suitable for normal crop growth. This low bulk density made root growth and penetration easier, and improved the size and system of voids in the soil matrix, enabling aeration and water movement. Furthermore, the particle size of the fertilizers ranged from 50 to $150 \mu \mathrm{m}$, and that of the soil was $\approx 300 \mu \mathrm{m}$, which is within the recommended range of 30 to $300 \mu \mathrm{m}$ for optimal plant development (Dresbøll, 2004).

The soil amended with the fertilizers had $\mathrm{pH}$ values between 6.7 and 6.9, which are considered optimum for the rapid development 
of most ubiquitous microorganisms. At this $\mathrm{pH}$ range, $\mathrm{N}$ loss from ammonia volatilization is prevented because this phenomenon occurs only at acidic $\mathrm{pH}$ values $(<6.0)$ (Swisher, 1982). Soil porosity was $\approx 83 \%$ and moisture at saturation was greater than $40 \%$; these levels were unaffected by fertilization. The lower water content of SBFs was attributed to the presence of insoluble carbohydrates, proteins, and $\mathrm{Ca}$ ions. The high moisture content in the soil near to field capacity was responsible for the high diversity of viable microbials during the legume developing phase. These, in turn, promoted mineralization and increased available N. The high population of aerobic bacteria found during the whole crop cycle eased $\mathrm{N}$ fixation from the fertilizers and from the atmosphere. Interestingly, $P . v u l$ garis was able to modify its own root environment to maximize nutrient uptake. Thus, the inherent absence of $\mathrm{N}$ in the unfertilized substrate forced the plant to increase the root pattern so the $\mathrm{N}$ demand could be obtained by microbial (especially fungi) $\mathrm{N}_{2}$ fixation, as reported previously (Celestin, 2013). However, this $\mathrm{N}$ uptake was not sufficient to achieve optimal plant growth in $P$. sativum because the unfertilized substrates showed the poorest growth rate in CS. Conversely, SS showed better crop quality than CS as a result of the greater content of $\mathrm{Si}, \mathrm{Mg}, \mathrm{Fe}$, and $\mathrm{Ca}$, which were absent in CS.

The high microbial content of the fertilizers mingled with those of the soil microflora, favoring the rapid development of bacteria and fungi, which decreased during the crop cycle. The initial microbial levels of the soil were $\approx 50,000 \mathrm{cfu} / \mathrm{g}$ and $100 \mathrm{cfu} / \mathrm{g}$ for mesoaerobic and fungi, respectively. One month after seeding, the microbial population increased; but, at the end of the crop cycle, the microbial population had already diminished. However, the population patterns varied depending on the type of fertilizer used. It is plausible that microbiota converted sugars, proteins, and carbohydrates initially present in the SBFs to assimilable nutrients in the soil.

The water vapor sorption isotherm describes the sorption and volatilization of diffusive and convective water vapor transport, and gives an idea of the shrink-swell capacity of a material (Arthur et al., 2016). The Young-Nelson model distinguishes between the tightly bound monolayer $\left(m_{m}\right)$, normally condensed externally adsorbed moisture $\left(m_{c}\right)$, and internally absorbed water $\left(m_{i}\right)$ in a particle. Figure $1 \mathrm{~A}$ shows that, during the first sorption stage $\left(a_{w}<0.45\right)$, the isotherms exhibited a convex shape as the water molecules rapidly sorb onto the available sorption sites until a monolayer is formed. The latter is then the result of the balance between the surface binding forces of the multilayer and water in the core. The shape of the isotherms during this first stage did not differ substantially among the different SBFs, but the profile was greater for SS and COF. Thereafter, there was a gradual increase in water content with $a_{w}$ until $\approx 0.80$, when an abrupt increase in water content was observed, especially for CSF, as a result of capillary condensation phenomena. Interestingly, most fertilizers showed a steady increase in monolayer and multilayer formation up to an $a_{w}$ value of 0.45 . Afterward, the water molecules, although still in vapor form, began to diffuse within the particle core, except for CS and SS, in which this process started at a very low $a_{w}$ value (Fig. 1B). The isotherms proved that water did not form a continuous monolayer because the multilayer and particle water absorption occurred simultaneously. This phenomenon has been attributed to the tendency of water molecules to cluster around exchangeable cations found in different soils (Tuller and Or, 2005). Because SBFs are composed mainly of chitin and proteins, the high electronegativity of $\mathrm{O}$ and $\mathrm{N}$ compared with $\mathrm{H}$ allows for a strong $\mathrm{H}$ bond interaction between the hydroxyl groups of these fertilizes and incoming water molecules. As a result, water molecules bind themselves as succeeding layers, rather to empty sites on the surface of the particle. Thus, the formation of a second layer probably started at a lower concentration than the one corresponding to monolayer formation. Clustering was expected to occur in most cases because the amount of water molecules on the particle was greater than the quantity that can be bound within the particle.

SS and CSF per se had an innate ability to take up and retain water within the particle pores, and was able to form multilayers, preserving the wet environment for optimal root and microbiota development. Conversely, CSF at all $a_{w}$ values showed the least tendency for clustering, but the largest sorption in the particle core (Fig. 1C). The deconvoluted curves show that the monolayer formation presented a type III Langmuir isotherm, whereas the curves for the multilayer sorption showed a type II isotherm. CSF had the greatest ability for water sorption beyond $0.5 a_{w}$, and the greatest ability for water absorption within the particle core. This sample also showed the greatest cation exchange capability and ionic conductivity. This agrees with previous studies that reported a relationship between high water sorption and ion exchange capability of the soil (Woodruff and Revil, 2011). Furthermore, the magnitude of multilayer formation in SBFs improved as the degree of hydrolysis increased, resulting from the formation of low-molecular weight carbohydrates.

The multivariate analysis rendered interesting facts about this study. The first three components explained $78 \%$ of data variability (Fig. 3). In the PCA plot, three great clusters are observed apart from the center. The first one shows the relationship between the fertilizer type and ash, Si, C, Al, O, absorption enthalpy $(\Delta H)$, water absorption $(B)$, and number of pods of $P$. vulgaris. The second cluster depicts the influence of $\mathrm{Ca}, \mathrm{P}$, $\mathrm{N}, \mathrm{pH}$, sugars, zeta potential, and pod length of $P$. sativum. The third cluster shows a

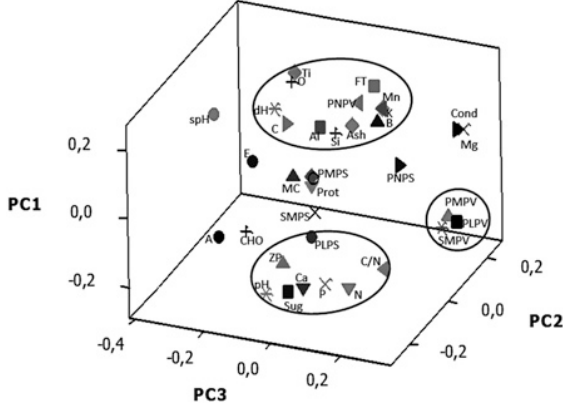

Fig. 3. Principal component (PC) plot showing the relationship between the fertilizers properties. $\mathrm{PC} 1=37.1 \%, \mathrm{PC} 2=15.8 \%$, and PC3 $=18.7 \%$ variability.

relationship among the crop quality features of $P$. vulgaris. Moreover, a correlation analysis confirmed the relationship between moisture content and water absorption within the particle core $(r>0.922)$. Likewise, fertilizers having a high ash content also had a high level of Si and $\mathrm{Al}(r>0.964)$.

AUAH converted useless shrimp waste into an alternative organic fertilizer with a low production cost. The raw waste showed optimal crop quality for both legumes, but a lower growth than CSF. The absence of $\mathrm{N}, \mathrm{Ca}$, and $\mathrm{P}$ in the unfertilized substrates limited legume growth and microbial activity. Thus, nutrient sufficiency ranges required minor adjustment for legume development. The viable microorganism population increased at the beginning of the crop cycle and then declined from a depletion of nutrients, but provided short-term fertility benefits for legume productivity. These fertilizers are considered more ecofriendly, more efficient, and accessible to marginal and small farmers located along the coast. SBFs were found to be an alternative soil amendment for legume crops grown using organic methods.

\section{Literature Cited}

Albalasmeh, A.A., A.A. Berhe, and T.A. Ghezzehei. 2013. A new method for rapid determination of carbohydrate and total carbon concentrations using UV spectrophotometry. Carbohydr. Polym. 97:253-261.

Aluko, O.A., T.O. Olanipekun, J.O. Olasoji, I.O. Abiola, O.N. Adeniyan, S.O. Olanipekun, E.C. Omenna, K.O. Kareem, and A.I. Douglas. 2014. Effect of organic and inorganic fertilizer on the yield and nutrient composition of Jute mallow. Glob. J. Agr. Res. 2:1-9.

American Society of Testing and Materials. 1995. Annual book of ASTM standards, designation D4972 - 95a: Standard test method for $\mathrm{pH}$ of soils. American Society of Testing and Materials, New York City, NY.

Aminul, M., A. Nasrulhaq, R. Motior, M. Sofian, and M. Aqeel. 2016. Effects of organic fertilizers on the growth and yield of bush bean, winged bean and yard long bean. Braz. Arch. Biol. Technol. 59:1-9.

Anderson, J.L., D. Valderrama, and J. Darryl. 2017. Shrimp production review: Global aquaculture alliance. Global Aquaculture Alliance, Dublin, Ireland.

Arthur, E.M., P.M. Tuller, and L.W. de Jonge. 2016. Evaluation of theoretical and empirical 
water vapor sorption isotherm models for soils. Water Resour. Res. 52:190-205.

Association of Official Analytical Chemists. 2005a. Official methods of analysis: Method 909.03: Total Kjeldahl nitrogen (direct method): Total nitrogen or crude protein. 18th ed. AOAC International, Rockville, MD.

Association of Official Analytical Chemists. 2005b. Official methods of analysis: Method 923.03: Ash of Flour (Direct Method). 18th ed. AOAC International, Rockville, MD.

Association of Official Analytical Chemists. 2005c. Official methods of analysis: Method 971.18: Official methods of analysis: Total carbohydrates, crude 'by difference' calculation: 100 percent minus percent $(\mathrm{CP}+\mathrm{Ash}+\mathrm{Crude}$ Fat + M). 18th ed. AOAC Interntional, Rockville, MD.

Brink, M. and G.E. Belay. 2006. Plant resources of tropical Africa 1: Conclusions and recommendations based on PROTA 1: Cereals and pulses. Backhuys, Leiden, The Netherlands.

Celestin, N.P. 2013. Effects of inorganic and organic fertilizers on nutrient uptake, soil chemical properties and crops performance in maize based cropping systems in eastern province of Rwanda. Kenyatta University. MSc. Environmental studies (Geoforesty and rural development), Nairobi, Kenya.

Chavan, B.L., M.M. Vedpathak, and B.R. Pirgonde. 2015. Effects of organic and chemical fertilizers on cluster bean (Cyamopsis tetragonolobus). Eur. J. Expt. Biol. 5:34-38.

Derkowska, E., L. Paszt, P. Trzcinsky, M. Przibyl, and K. Weszczak. 2015. Influence of biofertilizers on plant growth and rhizosphere microbiology of greenhouse-grown strawberry cultivars. Acta Sci. Pol. Hortorum Sultus 14:83-96.

Dresbøll, D.B. 2004. Optimization of growing media for organic greenhouse production. Royal Veterinary and Agricultural University, Denmark, PhD Diss.
Eroa, M.G. 2015. Production and characterization of organic fertilizer from Tubang-Bakod (Jatrophacurcas) seed cake and chicken manure. APJMR 3:9-13.

Esmaeilzadeh, J. and A. Gholamalizadeh. 2014. Influence of soil organic matter content on soil physical, chemical and biological properties. Intl. J. Plan. and Env. Sci. 4:244-252.

Ghimire, A. 2002. A review of organic farming for sustainable agriculture. Tribhuvan University, Rampur, Chitwan, Nepal, BsC.

Guppy, C.N., N.W. Menzies, P.W. Moody, and F.P.C. Blamey. 2005. Competitive sorption reactions between phosphorus and organic matter in soil: A review. Austral. J. Soil Res. 43:189-202.

Islam, M.A., A.N. Boyce, M.M. Rahman, M.S. Azirun, and M.A. Ashraf. 2016. Effects of organic fertilizers on the growth and yield of bush, winged bean and yard long bean. Braz. Arch. Biol. Technol. 59:1-9.

Kjartansson, G., S. Zivanovic, K. Kristbergsson, and J. Weiss. 2006. Sonication-assisted extraction of chitin from North Atlantic shrimps (Pandalus borealis). J. Agr. Food Chem. 54: 5894-5902.

Lekshmi, S., D.N. Singhb, and M.S. Baghini. 2014. A critical review of soil moisture. Measurement 54:92-105.

Leon, M.C.C., A. Stone, and R.P. Dick. 2006. Organic soil amendments: Impacts on snap bean common root rot and soil quality. Appl. Soil Ecol. 31:199-210.

Mahvi, A. 2009. Application of ultrasonic technology for water and wastewater treatment. Iran. J. Public Health 38:1-17.

Nelson, P.V., D.S. Pitchay, C.E. Niedziela, and N.C. Mingis. 2010. Efficacy of soybean-base liquid fertilizer for greenhouse crops. J. Plant Nutr. 33:351-361.

Romanyà, J., N. Arco, I. Solà-Morales, L. Armengot, and F.X. Sans. 2012. Carbon and nitrogen stocks and nitrogen mineralization in organically man- aged soils amended with composted manures. J. Environ. Qual. 41:1337-1347.

Silva, P.S.L.I., P.I.B.I.I. Silva, V.R.I.I.I. Oliveira, G.L.I.V. Barros, and A.L.V. Monteiro. 2013. Corn cultivar intercropping with arboreal legumes for weed control. Planta Daninha 31: 559-567.

Swisher, M.E. 1982. An investigation of the potential for the use of organic fertilizer on small, mixed farms in Costa Rica. University of Florida, Gainesville, FL, PhD Thesis.

Takahashi, K. 1981. Physiological disorders in Chinese cabbage, p. 225-233. In: N.S. Talekar and T.D. Griggs (eds.). Chinese cabbage. AVRDC, Shan hua, Taiwan.

Tucker, L.C. 2015. Comparison of two different organic fertilizer sources for flue-cured tobacco. Virginia Polytechnic Institute and State University, Agricultural and Life Sciences, Blackstone, VA, MSc.

Tuller, M. and D. Or. 2005. Water films and scaling of soil characteristic curves at low water contents. Water Resources Research 41:1-6.

Valdez-Perez, M.A., F. Fernandez-Luqueno, and O. Franco-Hernandez. 2011. Cultivation of beans (Phaseolus vulgaris) in limed or unlimed wastewater, sludge, vermicompost or inorganic amended soil. Scientia Hort. 128:380387.

Woodruff, W.F. and A. Revil. 2011. CEC-normalized clay-water sorption isotherm. Water Resour. Res. 47:1-15.

Yang, R., Y.Z. Su, T. Wang, and Q. Yang. 2016. Effect of chemical and organic fertilization on soil carbon and nitrogen accumulation in a newly cultivated farmland. J. Integr. Agr. 15:658-666.

Young, J.H. and G.L. Nelson. 1967. Research of hysteresis between sorption and desorption isotherms of wheat. Trans. ASAE 756761. 